\title{
Laparoscopic single-port sleeve gastrectomy for morbid obesity: preliminary series.
}

\author{
Gentileschi P, Camperchioli I, Benavoli D, Di Lorenzo N, Sica G, Gaspari AL.
}

\section{Source}

Bariatric Surgery Unit, Department of General Surgery, University of Rome Tor Vergata, Rome, Italy.

\section{Abstract}

\section{BACKGROUND:}

Laparoscopic sleeve gastrectomy has been recently proposed as a sole bariatric procedure because of the resulting considerable weight loss in morbidly obese patients. Traditionally, laparoscopic sleeve gastrectomy requires 5-6 skin incisions to allow for placement of multiple trocars. With the introduction of single-incision laparoscopic surgery, multiple abdominal procedures have been performed using a sole umbilical incision, with good cosmetic outcomes. The purpose of our study was to evaluate the feasibility and safety of laparoscopic single incision sleeve gastrectomy for morbid obesity.

\section{METHODS:}

A total of 8 consecutive patients underwent laparoscopic single-incision sleeve gastrectomy at the Operative Unit of Bariatric Surgery of the University of Rome Tor Vergata from March 2009 to June 2009.

\section{RESULTS:}

Of the 8 patients, 5 were women and 3 were men, with a mean age of 44.4 years. The mean preoperative body mass index was $56.2 \mathrm{~kg} / \mathrm{m}(2)$. The mean operative time was 128 minutes. The mean postoperative stay was 2.4 days. The mean postoperative body mass index was $49.3 \mathrm{~kg} / \mathrm{m}(2)$ at a mean follow-up period of 3.6 months. The mean percentage of excess weight loss was $33 \%$ for the same period.

\section{CONCLUSIONS:}

Laparoscopic single-incision sleeve gastrectomy seems to be safe, technically feasible, and reproducible. A randomized trial comparing single-incision sleeve gastrectomy and conventional sleeve gastrectomy might be needed to evaluate the postoperative results in relation to the development of abdominal wall complications.

Copyright () 2010 American Society for Metabolic and Bariatric Surgery. Published by Elsevier Inc. All rights reserved. 